\title{
Erratum to: hypospadias, all there is to know
}

\author{
H. J. R. van der Horst ${ }^{1}$ • L. L. de Wall ${ }^{2}$
}

Published online: 24 August 2017

(C) Springer-Verlag GmbH Germany 2017

Erratum to: Eur J Pediatr (2017) 176:435-441
DOI 10.1007/s00431-017-2864-5

The original version of this article, unfortunately, contained an error.

In the original article, the statement found on page 438 , left column, third paragraph, the bibliographic information of reference citation [12] should be the below:

Jones BC, O'Brien M, Chase J, Southwell BR, Hutson JM (2009) Early hypospadias surgery may lead to a better longterm psychosexual outcome. J Urol 182 (4 suppl): 1744-1749

The online version of the original article can be found at https://doi.org/ 10.1007/s00431-017-2864-5

H. J. R. van der Horst

h.vanderhorst@vumc.nl

L. L. de Wall

Liesbeth.deWall@radboudumc.nl

1 Department of Urology, VUmc, De Boelelaan 1117, P.O. Box 7057, 1007 MB Amsterdam, The Netherlands

2 Department of Urology, Radboudumc, Geert Grooteplein 10, P.O. Box 9101, 6500 HB Nijmegen, The Netherlands 